\title{
Tavattomat infinitiivit
}

\section{Eräiden myötätapahtumisen infinitiivirakenteiden konstruktiokielioppia suomen murteissa}

\author{
MARKUS HAMUNEN
}

\section{Väitöksenalkajaisesitelmä Helsingin yliopistossa 12. kesäkuuta 2019}

Joka aamu heti herättyämme - meille näkeville - elämä on yhtä katsomista, näkemistä, havainnointia. Teemme kaiken aikaa erityisesti näköhavaintoja, kuten X oN Y, X LIIKKUU Z:AAN, X:LLÄ ON Q ja X on L:ssä. Aivan tällaisten ei-kielellisten havaintojen ja erilaisten tuntemusten kannoilla seuraa mahdollisuus niiden kielentämiseen, siis esittämiseen kielellisessä muodossa. Tämä mahdollisuus usein myös käytetään: ${ }^{1}$

(1) Nainen $\sim$ mies $\sim$ Keijo on vanttera.

(2) Nainen juoksee metroon. Naisella on kiire.

(3) Mies hoipertelee metroon. Mies on humalassa.

(4) Keijo köpöttelee metroon. Keijolla on kyynärsauvat.

On sinänsä oma asiansa se, mitkä sanavalinnat ja mikä tarkkuusaste tarkalleen valitaan, millaisia päätelmiä havainnoista tehdään ja mikä on ilmaisijan tietoperusta. Kielellinen ilmaus viime kädessä kuitenkin muotoutuu tällaisia seikkoja silmällä pitäen ja tietysti käyttötarkoituksensakin mukaisesti. Yhtä kaikki kielijärjestelmänä kuvattavissa oleva, kielen konventionaalistunein osa tarjoaa runsaasti tuotto- ja tulkintamalleja esimerkiksi juuri havaintojen kielentämiselle. Edellä esitetyistä kielennyksistä (esimerkit 1-4) voidaan poimia muutama esimerkki taulukkoon 1.

1. Esimerkit ovat sepitettyjä. 
Taulukon 1 vasen sarake koettaa kuvata ei-kielellistä havaintoa tai tämän käsitteistystä tekemällä sen paradoksaalisesti kielellisesti - tämä on ilmentymä yhdestä kielentutkimuksen perustavasta metodisesta haasteesta: kuvata kieltä kielellä. Seuraavassa sarakkeessa on kielellisiä ilmauksia ottamatta kantaa kielennyksen tapaan (esim. mielessään puhuminen, kertominen, dialogi, kielentutkijan kielitajullaan operointi). Jälleen seuraavassa sarakkeessa on perinteisiä kieliopin rakennemalleja, joista kielennysten voi ajatella olevan yksittäisiä toteutumia.

\begin{tabular}{l|l|l|l}
$\begin{array}{l}\text { Ei-kielellinen } \\
\text { käsitteistys }\end{array}$ & Kielennys & $\begin{array}{l}\text { Kielennyksen } \\
\text { rakennemalli }\end{array}$ & Lausetyyppi \\
\hline 'X on Y' & Nainen on vanttera & $\mathrm{NP}+$ kop + NP AP & predikatiivilause \\
\hline 'X liikkuu Z:aan' & Mies hoipertelee metroon & $\mathrm{NP}+\mathrm{V}(+\mathrm{X})$ & intransitiivilause \\
\hline 'X:llä on Q' & Keijolla on kyynärsauvat & $\mathrm{NPposs}+\mathrm{kop}+\mathrm{NP}$ & omistuslause \\
\hline
\end{tabular}

Taulukko 1.

Käsitteistykset ja näiden vakiintuneet kielelliset rakennemallit kielenilmausten taustalla.

Huomataan, että kielennyksen mallit edustavat perinteisiä lausetyyppejä (taulukko 1, oik. sarake): predikatiivilause tai (luonnehtiva) kopulalause, intransitiivilause ja omistuslause. Terminologia on perinteisesti ollut kirjavaa ja kuvauskohtaista. Yhtä kaikki lausetyypit ovat kielenilmausten semanttis-rakenteellisia rankoja. Niiden merkityspuolta muistuttavat taulukon ei-kielelliset käsitteistykset. Niistä saadaankin kielen rakennerankojen merkityskuvaus kääntämällä ne jollain tavoin symbolimuotoon, toisin sanoen luomalla niille teoreettinen kuvauskieli. Tähän tarkoitukseen on kehitetty esimerkiksi semanttiset roolit, joilla kuvataan tyypillisesti verbin kuvaaman tapahtuman ympärille asettuvien erilaisten osallistujien semanttisia yleispiirteitä tai jollain tavoin keskeistä merkitystä.

Nyt yhdistämällä muoto (esim. peruslausetyyppien rakennetieto) ja merkitys (esim. semanttisten roolien kuvaus) päästään konstruktiokielioppi-nimisen kielenkuvausmallin perusajatukseen, jonka mukaan kielijärjestelmänä kuvattavat kielen konventionaalistuneet osat ovat usein - eivät kuitenkaan aina - konkreettisia ilmauksia abstraktimpia muoto-merkitys- tai rakenne-käyttö-yhdelmiä. Erityisesti tällaiset on nähty konstruktioina. Konstruktiokieliopissa ajatellaan, että koko kieli käyttöön otettavana varantona on alati jäsentymässä niin kieli- tai toimintayhteisöissä kuin yksilöiden mentaalikieliopeissa tähän tapaan konstruktioiksi ja niiden välisiksi suhteiksi. Kielioppi olisi kohdetta näin tarkastellen konstruktikko, tyyppien kokoelma, jossa on puolivalmisteita, valmiskappaleita ja abstraktimpia skeemoja tilanteiseen kielenkäyttöön sovellettaviksi. (Ks. esim. Fillmore \& Kay 1995.)

Tämän ajatuksen perusteet eivät ole uudet. Moni nimekäs lingvisti on tuonut saman idean esiin jo kauan ennen varsinaista konstruktiokielioppia, esim. Edward Sapir, Otto Jespersen, Charles Hockett ja jopa Leonard Bloomfieldkin kaikesta antimentalismistaan huolimatta (ks. Itkonen 2011; Hamunen 2015). Itse ajatus lienee vielä tätäkin vanhempi. Konstruktiokielioppi on kuitenkin nostanut tämän näkemyksen kuvausmallinsa keskiöön ja kyennyt samalla havainnollistamaan selvemmin niitä 
mentalistisia ideoita, joita esimerkiksi juuri jo varhaisessa strukturalismissa oli iduillaan. Tämä on onnistunut erityisesti kognitiivisen kielentutkimuksen laaja-alaisen suuntauksen alla.

Kuitenkin jossain määrin konstruktiokieliopin uskottavuuden ongelmaksi on muodostunut se, että teorian lippulaivaksi ovat vakiintuneet niin kutsutut argumenttirakennekonstruktiot. Ne ovat jonkin verran yksinkertaistaen edellä kuvattujen peruslausetyyppien ja niiden kaltaisten ilmaustyyppien kielikohtaisia ilmausten malleja. Melkeinpä klassinen esimerkki argumenttirakennekonstruktiosta on Adele Goldbergin (1995) kuvaama englannin AIHEUTETUN LIIKKEEN -argumenttirakennekonstruktio (CAUSED MOTION construction). Esimerkiksi englannin lauseet Elmer kicked the ball from the lawn, Sandra pushed the book into the shelf ja John ordered Elvis out of the building ovat tämän abstraktin konstruktion yksittäisiä toteutumia. Esimerkeistä nähdään, että konstruktio on semanttiselta rakenteeltaan muotoa 'X aiheuttaa Y:n liikkeen Z:aan (tai) Z:sta’.

Esimerkiksi englannin AIHEUTETUN LIIKKEEN -konstruktion itsenäinen asema niissä käytettyihin verbeihin nähden näkyy esimerkiksi ilmauksesta She sneezed the napkin off the table. Vaikka englannin verbin sneeze ('niistää) merkityksessä liike on korkeintaan hyvin perifeerinen merkityspiirre (niistämisen aiheuttama ilmavirran liike) ja aiheutuksen merkitystä ei ole ollenkaan, on ilmaus kuitenkin käypää englantia. Nämä merkitykset ja samalla ilmaustyypin muiden osien semanttiset roolit määrää abstrakti konstruktio.

Juuri tällä nimenomaisella argumentaatiolla konstruktiokieliopissa ajatellaan, että AIHEUTETUN LIIKKEEN ilmaustyypille on varattava itsenäinen asema englannin kieliopissa ja sitä vastaavassa kielioppikuvauksessa. Samalla tämä konstruktio ilmentää sitä, että kielenkuvaukselle relevantteja tasoja on myös konkreettisten ilmausten yläpuolella, noin vertauskuvallisesti ilmaisten. (Ks. myös Leino 2010.)

Konstruktiokieliopissa on valtaosin keskitytty kielikohtaisten idiomien, erilaisten idiosynkraattisten rakenteiden ja erityisesti edellä esitellyn argumenttirakennekonstruktion tapaisiin ilmiöihin. Argumenteiksi on nimetty vanhastaan (mm. dependenssikieliopissa) erityisesti verbin käsitteellisesti pakollisia kumppaneita, tyypillisesti esim. subjektia ja objektia. Konstruktiokieliopin näkökulmasta tilanne vastaa sitä, että argumentit määrää abstrakti konstruktio eivätkä niinkään yksittäiset verbit. Entä miten on tällöin suhtauduttava sellaisiin ilmausten osiin, jotka eivät ole argumentteja, jotka eivät ole pakollisia tai käsitteellisesti niin välttämättömiä kuin argumentit? Ilmauksiahan höystetään tavan takaa erilaisilla muilla aineksilla. Emmehän puhu tai kirjoita vain argumenttirakentein. Esimerkiksi adjunktit eli vapaat adverbiaalit muodostavat laajan joukon erilaisia aikaa, paikkaa, tapaa, keinoa, syytä, tarkoitusta ja muita merkityksiä kuvaavia ilmausten osia. Näistä konstruktiokielioppi ei tietääkseni ole toistaiseksi sanonut vielä paljoakaan, vaikka argumentti-adjunkti-jakoa voinee pitää jopa universaalina ominaisuutena luonnollisessa kielessä.

Käsillä oleva tutkimukseni iskee tähän kantaan: vastoin muinaisen nimettömän lingvistin neuvoa, "[m]itä ikinä teetkin, pysy loitolla adverbiaaleista", olen ottanut tarkasteltavaksi neljä suomen infiniittistä rakennetta, jotka joko ovat adjunkteja tai joissa 
on adjunktiksi tulkittava osa. ${ }^{2}$ Näitä ilmaustyyppejä havainnollistavat seuraavat esimerkit. Käyttämäni rakenteiden nimitykset ovat esimerkkien perässä.

(5) se hevonen kah sit läks mennä kytkyttää (LA, Suursaari) koloratiivirakenne

(6) tuli tuolta lotojen kärmes (DMA, Ylihärmä)

TEN-rakenne

(7) see kert selvittim puhumalk kyl (DMA, Honkilahti) MALLA-rakenne

(8) se lähti amenta sanomata (SMS, s. v. aamen, Nivala) MATTA-rakenne

Kohteena ovat siis koloratiivirakenne (esim. 5), TEN-rakenne (esim. 6), MALLArakenne (esim. 7) ja MATTA-rakenne (esim. 8). Tutkimukseni on suomen kieliopin tavanomaista perustutkimusta siinä mielessä, että olen valinnut juuri nämä suomen kieleen vakiintuneet spesifit ilmaustyypit tutkimukseni aiheeksi. Tutkimus on myös lausesemantiikan tutkimusta, sillä olen rajannut tarkastelun alaiseksi perinteistä lausetta vastaavan osan ilmauksista ja tutkin rakenteiden merkityksiä. Näin valitsemani infinitiivirakenteet tulevat tarkastelluiksi aivan välittömimmässä ilmausyhteydessään. Aineiston olen koonnut perinteisiä murteita sisältävistä lähteistä ja kokoelmista, sillä tällainen aines edustaa varmimmin autenttisinta infinitiivirakenteiden käyttöä suomessa ennen yleiskielen tasoittavaa ja kielenhuollon ohjailevaa vaikutusta. Aineistoa on tuhansia esimerkkejä.

Kysyn väitöskirjassani seuraavaa: 1) Millainen on kunkin valitun infinitiivirakenteen päämerkitys tai merkitys ylipäätään? 2) Millaisia infinitiivirakenteita nämä ovat ja 3) miten konstruktiokielioppi soveltuu näiden rakenteiden kuvaamiseen? Vastaan tässä tiiviisti kuhunkin kysymykseen.

Ensiksi kaikki kuvaamani rakenteet ovat käytöltään polyseemisia eli monimerkityksisiä. Jopa koloratiivirakenne kiinteänä ja idiomaattisena suomen ilmaustyyppinä osoittaa hämmästyttävää semanttista taipuisuutta. Tutkimusartikkelissani "Koloratiivirakenne, liike ja tapa" (Hamunen 2012) osoitan, että esimerkiksi liikettä kuvaavissa tapahtumissa koloratiivinen verbi voi merkityksellään kohdistua liiketapahtuman eri osiin: liikkujaan, itse liikkeeseen, liikkeen väylään, liiketapahtuman muuhun osaan tai johonkin liikkeestä muuten seuraavaan (esim. siitä syntyvään ääneen). Siis hyvin monipuolisesti liikekehyksen eri osiin.

Samoin TEN-, MALLA- ja MATTA-rakenteet ovat monimerkityksisiä. Niissä finiittimuotoisen kehysrakenteen ja tätä modifioivien, mainittujen infinitiivirakenteiden erilaiset kieliopilliset piirteet ovat keskinäisessä yhteydessä erilaisin kombinaatioin siten, että syntyy kuvaamiani (varsinaisen) tavan, keinon, oheisteon ja menettelytavan merkityksiä, kuten olen tutkimusartikkelissani "Juosten vai juoksemalla?" (Hamunen 2017) osoittanut. Infinitiivirakenteilla ei siis tarkasti katsoen ole yhtenäistä päämerkitystä, vaan niiden merkitykset ovat aidosti kontekstuaalisesti kehkeytyviä. $\mathrm{Ne}$

2. Alkuperäinen sitaatti kuuluu: "Whatever you do, stay away from adverbs" (Fillmore 1994: 160). Neuvo on osuva myös adverbiaalien kannalta. Adverbit ovat usein syntaktisesti adverbiaaleja. 
kuvaavat, mitä tapahtuu finiittirakenteen kuvaaman tapahtuman ohessa. Näin ne adjunktisuhteen myötä kuvaavat myös sitä, miten finiittiverbillä kuvattu tapahtuma toteutuu.

Toiseksi tutkimani infinitiivirakenteet muodostavat kaksi ryhmää. Koloratiivirakenne muodostaa idiosynkraattisuuttaan oman joukkonsa. Siinä A-infinitiivi toimii ikään kuin toiminnan tai tapahtuman nimeävänä nimilappuna, jota koloratiivinen verbi merkityksellään luonnehtii, josta se nostaa esiin erilaisia, usein hankalasti kielennettäviä vaikutelmia ja jonka nimeämässä kehyksessä se fokusoi johonkin tiettyyn osaan kuvatun tapahtuman kokonaisuudessa.

TEN-, MALLA- ja MATTA-rakenne puolestaan muodostavat keskenään lähikonstruktioiden ryhmän. Niillä on riittävästi yhteisiä rakenteellisia ja funktionaalisia ominaisuuksia, jotta niiden voi ajatella muodostavan keskenään läheisten ilmaustyyppien ryhmän. Aikaisempi fennistiikka on puhunut - oikeaa jälkeä seuraten mutta melko tavalla ylimalkaisesti - yleisesti tavan ja keinon infinitiiveistä. Osoitan tällä tutkimuksellani, että tapa ja keino ovat vain yhdenlaisia vaikkakin keskeisiä näiden infinitiivien merkityksiä. Ne ovat merkityksiä, jotka siis kehkeytyvät finiittirakenteiden ja infinitiivirakenteiden tiettyjen kieliopillisten piirteiden integroituessa. Näitä vaikuttavia kieliopillisia tekijöitä ovat verbien väliset temporaaliset tulkinnat, tekijyyttä tai subjektia koskevat tulkinnat, verbien keskinäinen leksikaalinen semantiikka, kausatiivisuus ja negaatio. Kutsunkin tutkimiani rakenteita myötätapahtumisen infinitiivirakenteiksi. Ne kuvaavat adjunkteina sellaisia tapahtumia, jotka tulevat tulkituiksi suhteessa finiittiverbillä kuvattuun päätapahtumaan. MATTA-rakenne asettuu vielä TEN- ja MALLA-rakenteen vastinpariksi siten, että se kuvaa kielteistä myötätapahtumista, siis jotain mitä ei tapahdukaan finiittirakenteen ohessa (ks. Hamunen 2018).

Kolmanneksi olen valittujen rakenteiden kuvauksessani käyttänyt hyväksi kognitiivisen kielentutkimuksen sekä erityisesti konstruktiokieliopin teoreettisia käsitteitä sekä kuvauskeinostoa. Tähän on perusteltu syy: pyrin esittämään kuvaamistani rakenteista ja niiden semantiikasta yleistyksiä, siis niitä kieliopillisia tekijöitä ja mekanismeja, jotka toimivat yksittäisten infinitiivi-ilmausten taustalla. Lisäksi esim. kognitiivisen kieliopin piktografiset mallit (esim. Langacker 1987: 245) - käytännössä piirrokset - ovat toimiva keino kuvata kieleen koodautunutta semantiikkaa ei-kielellisesti. Menemättä tässä tarkemmin kuvaukseni yksityiskohtiin, soveltamani konstruktiokielioppi ei tarjoa formalismissaan mitään helppoa ja valmista keinoa kuvata myötätapahtumisen infinitiivirakenteita. Onkin myönnettävä, että formalismini on siksi jossain määrin ad hoc -tyyppistä, juuri tämän ilmiön kuvaamiseen kehiteltyä.

Kuitenkaan formalismin rosoisuus tai tietty käymättömyys ei johdu ensi sijassa käytetyn teorian puutteista tai keskeneräisyyksistä vaan paljolti myös itse kuvauskohteesta. Kieli ei jäsenny tiukkarajaisiin kategorioihin. Kielenilmaukset eivät luokitu siisteihin ryhmiin pakottamatta. Kieli ei ole yksi yhteen tietokoneohjelmaan verrattavaa koodia. Kielen voi kuitenkin nähdä ihan perustellusti myös järjestelmänä. Tällaisena se on suboptimaali (Nyman 1974). Ihminen kognitiivisine kykyineenkään ei ole täydellinen, ja kieli on ihmisen. Kun näin on, sen sopii näkyä myös kielenkuvauksessa. Siitä huolimatta juuri erilaiset formaalistamisen tavat ja muodot ovat nähdäkseni yksi toimiva ja hyväksyttävä keino esittää yleistyksiä kielestä. Jossain konstruktiokieliopissa tämä on 
erityisen perusteltua (mutta ei millään lailla kuitenkaan pakollista), koska tavoitellaan kuvaa konkreettisia ilmauksia abstraktimmasta kielen skeemavarannosta.

Metodiset ja teoreettiset valinnat ja ratkaisut tarjoavat mahdollisuuden vielä kiinnittää yleisempääkin huomiota kielentutkimukseen kokonaisvaltaisena, luonnollista kieltä tutkivana tieteenalana. Nimittäin erityisesti funktionaaliseksi kielentutkimukseksi nimitetty kielentutkimuksen suuntausperhe on tehnyt täyden päivätyön irtautuakseen retorisesti kilpailijaksi nähdystä ja aikanaan tieteensosiologisesti valta-asemassa olleesta generatiivisesta kielentutkimuksesta. Suomalaisessa kielentutkimuksessa funktionalismin peitto on melko kattava. Esimerkiksi generativisteja ei ole Suomessa ollut koskaan montaa, ei varsinkaan pitkäaikaisesti.

Tieteessä halutaan synnyttää retorisia käänteitä. Se on muiden asioiden muassa pelitilan raivaamista uusille näkemyksille ja tutkimussuuntauksille. Tällaisen seurannaisja kerrannaisvaikutuksena syntyy kuitenkin usein arvottavia tai jännitteisiä puhetapoja, joita harkitsevan tutkijan ei aina kannata loppuun asti seurata vain välitön tieteellinen menestys tai paikallinen muoti silmämääränään. Erityisesti funktionaalisessa kielentutkimuksessa on nähtävissä, että esimerkiksi sellaiset termit kuin kielitaju tai kielellinen introspektio tai kielellinen intuitio (vs. autenttinen kielenaines ja korpusmateriaali), kielenkuvausmalli tai kieliteoria (vs. kielen käyttötapausten kuvaaminen) ja formaali kuvaustapa tai formalismi (vs. proosallinen esitys) ovat jotenkin pannassa tai kyseenalaisia. Niillä on jollain tavoin alennettu arvo funktionaalisen kielitieteen retorisilla markkinoilla.

Kuitenkin jo tällaisten tutkimusta koskevien dikotomioiden esittäminen johtaa helposti yksinkertaistamaan tutkimuksen reaalista luonnetta liikaa. Kielentutkija voi, vain yhtenä esimerkkinä esittääkseni, havainnoida vaikkapa keskusteluaineistossaan ilmenevän dialogipartikkelin käyttöä ja osoittaa, millainen vuorovaikutusfunktio sillä on käyttöyhteydessään, siis mitä sillä tehdään. Hän voi myös - aivan legitiimisti - pohtia, miten samaa kielenkäyttötilannetta olisi tulkittava, mikäli partikkeli ei esiintyisikään tarkastelun alla olevassa esimerkissä. Tämä ei ole tavatonta, vaan kyse on perinteisestä minimiparianalyysista. Molemmissa analyyseissa käytetään kielitajua. Jälkimmäisessä vaan sikäli enemmän, että aineisto ei enää ole yhtä autenttista kuin edellisessä vaan kieli-intuition validoimaa.

Jos nyt tarkastellaan vielä luonnollista kieltä kokonaisuutena, kuva näyttää kutakuinkin kuvion 1 kaltaiselta.

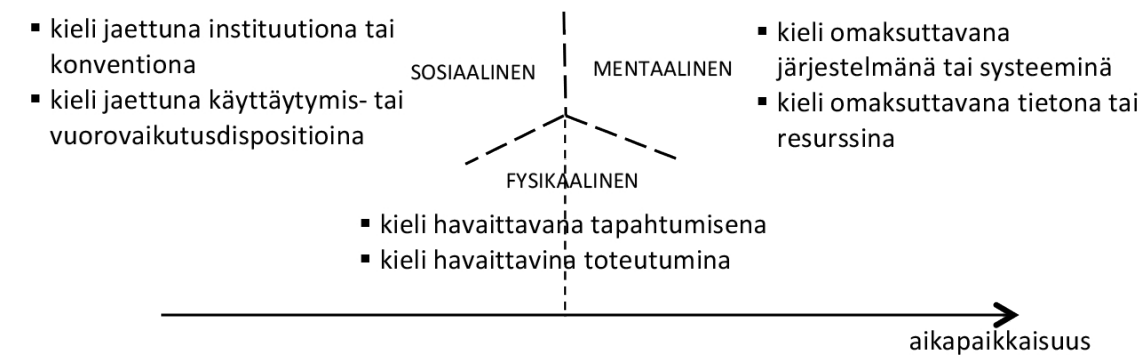

Kuvio 1.

Näkökulmia kieleen. 
Kuvio 1 on tietenkin karkeistus ja yksinkertaistus. Silti ei ole vaikea havaita, että kieli näyttäytyy tutkimukselle hyvin monimuotoisena; kielellä on monta ilmenemismuotoa tai onttista olotilaa. Näin ollen on myös täysin johdonmukaista, että kieltä tutkitaan näiden olomuotojen oletettuja ominaispiirteitä tavoitellen, monesta eri näkökulmasta. Se on pelkästään järkevää.

Kielentutkimuksen metodologisessa diversiteetissä on juuri siksi erilaisilla kielenkuvausmalleilla, kielitajun käytöllä ja formaalillakin kuvauksella aivan varteenotettava asemansa vielä huomennakin, myös konstruktiokieliopilla. Kieli on epäilyksittä intersubjektiivista ja tekstuaalista toimintaa, käyttäytymistä, sosiaalista vuorovaikutusta, kieli tapahtuu, se on käyttöön otettava resurssi ja niin edelleen. Kieli on siis olennaisesti jotain sellaista, mikä on havaittavissa aikapaikkaisesti. Mutta moni kielen ilmenemistaso tai näkökulma tarjoaa kielestä kuvauksen ja eksplikaation kohteeksi jonkin abstraktin tason, joka irtoaa välittömästä aikapaikkaisuudesta, tästä empiirisyyden primaariksi ymmärretystä tasosta. Tätä abstraktimpaa tasoa esimerkiksi juuri konstruktiokielioppi pyrkii kuvaamaan ja teoreettisesti eksplikoimaan: Ihminen yleistää. Ihmisen eemistämiskyky ja -taipumus on oikeastaan edellytys kaaosmaisessa maailmassa toimimiselle (vrt. käsitepari emic ja etic). Erilaiset kielelliset skeemat, skriptit ja konstruktiot tarjoavat siksi käyttökelpoisia malleja kielelliselle toiminnalle. Samasta syystä on myös mielekästä ja perusteltua koettaa kuvata näitä, eikä konstruktiokielioppi ole tähän aivan kehno vaihtoehto.

Lopuksi voi todeta, ettei yhdenkään kielentutkimuksen suuntauksen ole tarvetta sinänsä puolustella erikseen olemassaoloaan muuten kuin tieteen yleisten pelisääntöjen mukaisesti. Se ei ole minunkaan tarkoitukseni. Sen sijaan maineikkaan kognitiivisen kielentutkimuksen edustajan Leonard Talmyn lausahduksessa piilee viisaus: "there is no gold standard in linguistics" (Talmy 2007: xi). Kielentutkimuksessa ei ole yhtä suuntausta, teoriaa, metodia, koulukuntaa tai kielikäsitystä, joka olisi ylitse muiden, joka pätisi kaikkialla ja kattaisi keskeisimmän osan luonnollisesta kielestä. Vain yksinomainen lingvistiikka on potentiaalisesti vahingollista tai ei-ideaalia. Siitä meillä on tunnettuja historiallisia esimerkkejä (ks. esim. Karlsson 1975). Siksi suomalaisen ja nyt kohdallamme paikallisemmin helsinkiläisen kielentutkimuksen onkin yhä ja alinomaa vaalittava mahdollisimman monipuolista tutkimuskulttuuria. Näkemykseni mukaan, erityisesti kielenkuvausmallien tai -teorioiden näkökulmasta, Talmyn lausahduksesta jää meille tässä suhteessa vielä jonkin verran ymmärrettävää.

\section{Lähteet}

Fillmore, Charles J. 1994: Under the circumstances (place, time, manner, etc.). Proceedings of the twentieth annual meeting of the Berkeley Linguistics Society. General session dedicated to the contributions of Charles J. Fillmore s. 158-172. Berkeley: Berkeley Linguistics Society. http://dx.doi.org/10.3765/bls.v20i1.1478.

Fillmore, Charles \& Kay, Paul 1995: Construction Grammar. CSLI Lecture Notes. Stanford, CA: Center for the Study of Language and Information.

GOLDBERG, Adele E. 1995: Constructions: a construction grammar approach to argument 
structure. Chicago: University of Chicago Press.

Hamunen, Markus 2012: Koloratiivirakenne, liike ja tapa. - llona Herlin \& Lari Kotilainen (toim.), Verbit ja konstruktiot s. 104-140. Suomi 201. Helsinki: Suomalaisen Kirjallisuuden Seura.

- 2015: Analogian käsitteestä konstruktiokieliopissa. - Virittäjä 119 s. 278-286.

- 2017: Juosten vai juoksemalla? Infiniittisten TEN- ja MALLA-rakenteiden semantiikkaa ja murrejakaumaa. - Sananjalka 59 s. 125-153.

— 2018: MATTA-rakenteen kognitiivista semantiikkaa. - Virittäjä 122 s. 356-386. https://doi. org/10.23982/vir.64471.

It KONEN, EsA 2011: Konstruktiokielioppi ja analogia. - Virittäjä 115 s. 600-605.

KARlsson, Fred 1975: Fennistiikan tieteenparadigmasta ja sen ohjausvaikutuksesta. - Virittäjä 79 s. 179-193.

Langacker, Ronald W. 1987: Foundations of Cognitive Grammar. Volume 1. Theoretical Prerequisites. Stanford (Cal.): Stanford University Press.

Leino, JАакко 2010: Adele E. Goldberg - Väitöskirjalla klassikoksi. - Pentti Haddington \& Jari Sivonen (toim.), Kielentutkimuksen modernit klassikot. Kognitiivinen ja funktionaalinen kielitiede s. 71-97. Helsinki: Gaudeamus.

Nyman, Mart ti 1974: Synkronisen rekonstruoinnin rajat. - Virittäjä 78 s. 223-242.

Talmy, Leonard 2007: Foreword. - Monica Gonzalez-Marquez, Irene Mittelberg, Seana Coulson \& Michael J. Spivey (toim.), Methods in cognitive linguistics s. xi-xxi. Human cognitive processing 18. Amsterdam: John Benjamins Publishing company. https://doi. org/10.1075/hcp.18.

Markus Hamunen: Tavattomat infinitiivit. Eräiden myötätapahtumisen infinitiivirakenteiden konstruktiokielioppia suomen murteissa. Helsinki: Helsingin yliopisto 2019. Artikkeliväitöskirjan johdanto on luettavissa osoitteessa https://helda.helsinki.fi/handle/10138/301732.

Kirjoittajan yhteystiedot:

etunimi.sukunimi@helsinki.fi 